\title{
An evaluation of dental information sessions provided to childcare educators in NSW in 2010-2011
}

\author{
Jennifer M. Noller \\ Centre for Oral Health Strategy, NSW Ministry of Health \\ Email: jennoller@bigpond.com
}

\begin{abstract}
Childcare services provide ideal settings to promote good oral health and help reduce tooth decay in young children. This paper reports the results of an evaluation of the dental information session component of the NSW Little Smiles Program provided by public oral health service professionals to childcare educators in NSW in 2010-2011. The evaluation sought to determine if a face-to-face information session provided to childcare educators by oral health professionals: (i) can improve the confidence of childcare educators to reach national quality standards that relate to oral health; and (ii) is an appropriate model to use. In 2010-2011, 163 dental information sessions were provided to 1716 participants from over 526 childcare centres across NSW. Results showed that a dental information session can improve the confidence of childcare educators to assist their service to reach the required national quality standards for oral hygiene and diet-related oral health issues. Further evaluation is required to determine if oral health can be embedded in the daily practice of childcare services and other options need to be explored to deliver the sessions in a more cost-effective way.
\end{abstract}

Tooth decay is the single most common chronic childhood condition and early childhood caries is a significant public health problem affecting preschool children. ${ }^{1}$ It crosses all socioeconomic boundaries ${ }^{2}$ and is associated with limited exposure to fluoride, early intake of sugary foods, drinks and snacks, and may occur in young children who are given pacifying bottles of juice, milk or formula, or soft drink or cordial to drink for prolonged periods during the day or overnight. ${ }^{3,4}$ Severe tooth decay in young children causes pain, problems with sleep and may impede growth. ${ }^{5}$ Tooth decay in young children is a disease of disadvantage. About 20\% of Australian 4-year old children examined in public dental clinics in 2000 had $90 \%$ of the tooth decay for that age group. ${ }^{6}$ The most recent New South Wales (NSW) Child Dental Health Survey in 2007 showed that by the time they started school almost $40 \%$ of children aged 5 and 6 years had experienced some decay in their deciduous (baby) teeth. ${ }^{7}$

Settings such as childcare centres are ideal locations in which to provide oral health promotion interventions ${ }^{8}$ and there is evidence that effective collaboration between parents, directors of childcare centres, and health professionals has the potential to improve the breadth and effectiveness of health promotion education. ${ }^{9}$ Data from the Australian Bureau of Statistics suggest that in 2011, $35 \%$ of NSW children aged $0-5$ years attended some form of formal care. ${ }^{10}$

In 2005 the National Childcare and Accreditation Council produced the Quality Improvement and Accreditation System Quality Practice Guidelines for childcare facilities. This document detailed the quality areas and principles that facilities were assessed against for accreditation purposes. In terms of oral health, facilities were required to have in place practices that met Quality Area 6: Health, Nutrition and Wellbeing; Principle 6.3: Staff encourage children to follow simple rules of hygiene. This could be met by putting in place: (i) a dental care policy that was based on advice from recognised health authorities; and (ii) procedures that helped children understand the importance of healthy teeth and learning to become responsible for their own personal hygiene and dental care practices. $^{11}$

Historically, childcare service providers in NSW met this standard by requesting a visit by oral health professionals from public dental services to provide oral health education to children at their centre. However, this strategy was not sustainable as it was human resource intensive and there is no evidence that providing one-off dental hygiene instruction to young children will result in long-term behavioural change. ${ }^{12}$ This resulted in the development of the NSW Little Smiles Program. 
This paper reports the results of an evaluation of the dental information session component of the NSW Little Smiles Program provided by public oral health service professionals to childcare educators in NSW in 2010-2011. The evaluation sought to answer two questions:

- Can a face-to-face dental information session improve the confidence of childcare educators to reach the required national quality standards for oral hygiene and diet-related oral health issues in childcare facilities?

- Is a face-to-face dental information session an appropriate model to use?

\section{Methods}

The NSW Little Smiles Program (the Program) was developed in 2008 by the Centre for Oral Health Strategy (COHS), NSW Ministry of Health. It focuses on providing childcare educators with basic oral health information required to meet the National Childcare and Accreditation Council assessment standards for oral hygiene and dietrelated oral health issues. The Program consists of a NSW Little Smiles Dental Health Resource Package for Childcare Professionals ('resource package'), ${ }^{13}$ and a dental information session ('session').

The development of the Program was guided by the NSW Little Smiles Advisory Committee, consisting of a range of oral health and childcare professionals with expertise in oral health and the quality standards required for accreditation of childcare facilities.

In March 2010 the NSW Chief Dental Officer sent a letter to all 3300 childcare services (preschool and long daycare) listed on a database provided by the then NSW Department of Community Services. The letter described the contents of the resource package and offered recipients the opportunity to receive, free of charge, the resource package and/or a dental information session by completing a yes/no form and faxing it back to COHS.

Over 1600 childcare services requested a resource package (around $50 \%$ of services on the database) and over 526 requested an information session. COHS provided Local Health District (LHD) Oral Health Promotion Coordinators (or representatives) with information necessary for the organisation and delivery of the sessions (e.g. details of the childcare services within their LHD that requested a session, and a USB containing: guidelines and a checklist for the sessions; a PowerPoint presentation; notes for presenters and participants; evaluation forms; and a sample certificate of attendance). Different methods were used by LHDs to organise and deliver the sessions: in some cases one person took sole responsibility for every task, while in others the workload was shared by oral health professionals, dental assistants, and administrative staff.

Sessions were held either during working hours or after hours, depending on approval from childcare centre management. Staff conducting sessions after hours were paid overtime, travel time and, where appropriate, for accommodation and meals. Some LHDs used a 'host' centre to conduct the sessions. The 'host' centre provided the venue for a number of childcare educators from different centres to attend the sessions. The sessions took up to 2 hours and provided basic oral health information about teeth, tooth decay, prevention, and how to refer to and access public dental services.

Before each session began participants were asked to complete a pre-confidence questionnaire, using a Likert scale, to determine their confidence in a number of areas of oral health: explaining why baby teeth are important; causes of tooth decay; how to prevent tooth decay; identifying tooth decay in young children; why oral health is an important issue for childcare staff; providing dental referral advice to parents; and using the resource package. The same questionnaire was provided after the session to determine increases in confidence. Participants were also provided with an evaluation form to complete at the end of the session to rate the organisation, content and delivery of the session. Additionally, a take home package was provided to session attendees, containing participants' notes and a copy of the resource package if they had not already received one.

\section{Results}

A total of 163 sessions were provided to 1716 participants from over 526 childcare services across NSW. One LHD did not provide information about the number of childcare services that received the sessions, and three LHDs did not participate in providing the sessions (Table 1).

The organisation and delivery of sessions varied due to staffing and structures across LHDs. There were several challenges involved in the organisation process and session delivery, such as costs for session presenters (e.g. travel, accommodation, meals, paid overtime) and small attendance numbers or failure to attend by childcare workers (for various reasons); consequently, some of the sessions were uneconomical.

Of the 1716 participants, 1401 (82\%) completed the session evaluation form. The majority of survey respondents reported that the organisation, content and delivery of the session were either 'very good' $(>30 \%)$ or 'excellent' ( $>50 \%$ ) (Table 2). Comments included:

- small groups allowed for discussion and clarification

- sessions were well organised, professionally executed, and well aimed at the target group as a refresher course

- presenters were approachable and made it easy to ask questions

- information was presented in a clear and easy to understand manner. 
Table 1. Dental information sessions provided by Local Health Districts as part of the NSW Little Smiles Program, 2010-2011

\begin{tabular}{lccc}
\hline Local Health District $^{\text {a }}$ & $\begin{array}{c}\text { Participants } \\
(n)\end{array}$ & $\begin{array}{c}\text { Information sessions } \\
(n)\end{array}$ & $\begin{array}{c}\text { Childcare services } \\
(n)\end{array}$ \\
\hline Far West & 0 & 0 & 0 \\
Hunter New England & 96 & 9 & 22 \\
Southern NSW and Murrumbidgee & 552 & 79 & 103 \\
Northern NSW and Mid North Coast & 0 & 31 & 0 \\
Northern Sydney and Central Coast & 611 & 2 & 145 \\
South Eastern Sydney and Illawarra Shoalhaven & 46 & 22 & 176 \\
Sydney and South Western Sydney & 252 & 6 & Not provided \\
Western NSW & 39 & 14 & 60 \\
Western Sydney and Nepean Blue Mountains & 120 & 163 & $>526$ \\
Total & 1716 & 0 \\
\hline a At the time of the evaluation Area Health Services were transferring to Local Health Districts. This table represents the names of the Local Health \\
Districts but have been combined to represent how they participated in the evaluation as Area Health Services.
\end{tabular}

Table 2. Participants' views on conduct of dental information sessions provided as part of the NSW Little Smiles Program, 2010-2011

\begin{tabular}{lcccccc}
\hline & No response & Poor & Fair & Good & Very good & Excellent \\
\hline Organisation & 14 & 1 & 26 & 156 & 485 & 719 \\
& $(1.0 \%)$ & $(0.1 \%)$ & $(1.9 \%)$ & $(11.1 \%)$ & $(34.6 \%)$ & $(51.3 \%)$ \\
Content & 1 & 2 & 16 & 120 & 453 & 809 \\
& $(0.1 \%)$ & $(0.1 \%)$ & $(1.1 \%)$ & $(8.6 \%)$ & $(32.4 \%)$ & $(57.7 \%)$ \\
Session delivery & 4 & 2 & 19 & 123 & 455 & 798 \\
& $(0.2 \%)$ & $(0.1 \%)$ & $(1.4 \%)$ & $(8.8 \%)$ & $(32.5 \%)$ & $(57.0 \%)$ \\
\hline$N=1401$ & & & & & &
\end{tabular}

The information that participants found most useful related to baby teeth (e.g. using bottles, dummies and cups), the tooth decay process, and toothbrushing techniques. Suggested session improvements included: a more hands-on and interactive presentation with practical demonstrations; and more handouts, brochures for parents, samples of resources and oral hygiene products, and a list of public dental clinics in the area.

Ninety-three percent of all participants $(n=1590)$ completed the confidence level questionnaires. There were increases in the proportion of participants who felt 'very confident' in all areas assessed (Table 3), with between $30 \%$ and $40 \%$ more participants stating that they felt 'very confident' for each area, after the session.

\section{Discussion}

The approach of integrating oral health into childcare services by providing an in-service oral health training program is supported by the Australian Community Services and Health Industry Skills Council ${ }^{14}$ and the American Academy of Pediatric Dentistry (AAPD) policy on childcare centres. ${ }^{15}$ One of the AAPD policy statements encourages childcare centres to provide in-service training programs for personnel regarding oral hygiene concepts, proper nutrition choices, the links between diet and tooth decay, and responses to traumatic injuries and their dental consequences.

This evaluation found that participants of the face-to-face dental information session component of the NSW Little Smiles Program increased their confidence in all areas covered by the sessions and the program was well received.

About $16 \%$ of the childcare services in NSW from urban and rural areas participated in this study, however the 1716 participants represented an average of nine participants per session. Although an assessment of the fidelity of the program delivery is beyond the scope of this study, for sessions to be more cost-effective greater numbers of participants per session would be beneficial. This could be achieved by offering Continuing Professional Development points to childcare educators as an incentive to boost session attendance or considering other options such as online training, which has been shown to be comparable to face-to-face instruction in terms of participant outcomes. ${ }^{16}$ Online education does not involve extensive travel 
Table 3. Pre and post confidence level results, dental information sessions delivered as part of the NSW Little Smiles Program, 2010-2011

\begin{tabular}{|c|c|c|c|c|c|c|}
\hline Topic & & Not confident & Some confidence & Confident & Very confident & No response \\
\hline Use the NSW Little Smiles & pre & 555 (34.9\%) & $502(31.6 \%)$ & $354(22.3 \%)$ & $122(7.7 \%)$ & $57(3.6 \%)$ \\
\hline Dental Health Resource & post & $7(0.4 \%)$ & $106(6.7 \%)$ & $774(48.7 \%)$ & $615(38.7 \%)$ & $88(5.5 \%)$ \\
\hline $\begin{array}{l}\text { Package for Childcare } \\
\text { Professionals }\end{array}$ & Difference & $34.5 \% \downarrow$ & $24.9 \% \downarrow$ & $26.4 \% \uparrow$ & $31.0 \% \uparrow$ & $1.9 \% \uparrow$ \\
\hline \multirow{3}{*}{$\begin{array}{l}\text { Identify why oral health } \\
\text { is an important issue } \\
\text { for childcare staff }\end{array}$} & pre & 107 (6.7\%) & $593(37.3 \%)$ & 607 (38.2\%) & 241 (15.2\%) & $42(2.6 \%)$ \\
\hline & post & $1(0.1 \%)$ & $51(3.2 \%)$ & 714 (44.9\%) & 786 (49.4\%) & $38(2.4 \%)$ \\
\hline & Difference & $6.6 \% \downarrow$ & $34.1 \% \downarrow$ & $6.7 \% \uparrow$ & $34.2 \% \uparrow$ & $0.2 \% \downarrow$ \\
\hline \multirow{3}{*}{$\begin{array}{l}\text { Explain why 'baby' teeth } \\
\text { are important }\end{array}$} & pre & 217 (13.6\%) & $677(42.6 \%)$ & $480(30.2 \%)$ & 167 (10.5\%) & $49(3.1 \%)$ \\
\hline & post & $4(0.3 \%)$ & $48(3.0 \%)$ & $697(43.8 \%)$ & 807 (50.8\%) & $34(2.1 \%)$ \\
\hline & Difference & $13.3 \% \downarrow$ & $39.6 \% \downarrow$ & $13.6 \% \uparrow$ & $40.3 \% \uparrow$ & $1.0 \% \downarrow$ \\
\hline \multirow{3}{*}{$\begin{array}{l}\text { Identify tooth decay } \\
\text { in young children }\end{array}$} & pre & $225(14.2 \%)$ & $689(43.3 \%)$ & $466(29.3 \%)$ & 155 (9.7\%) & $55(3.5 \%)$ \\
\hline & post & $3(0.2 \%)$ & 71 (4.5\%) & $730(45.9 \%)$ & 730 (45.9\%) & $56(3.5 \%)$ \\
\hline & Difference & $14.0 \% \downarrow$ & $38.8 \% \downarrow$ & $16.6 \% \uparrow$ & $36.2 \% \uparrow$ & $0.0 \%$ \\
\hline \multirow{3}{*}{$\begin{array}{l}\text { Provide dental referral } \\
\text { advice to parents }\end{array}$} & pre & 447 (28.1\%) & $611(38.5 \%)$ & $371(23.3 \%)$ & 119 (7.5\%) & $42(2.6 \%)$ \\
\hline & post & 16 (1.0\%) & 124 (7.8\%) & 736 (46.3\%) & 637 (40.1\%) & 77 (4.8\%) \\
\hline & Difference & $27.1 \% \downarrow$ & $30.6 \% \downarrow$ & $23.0 \% \uparrow$ & $32.6 \% \uparrow$ & $2.2 \% \uparrow$ \\
\hline \multirow{3}{*}{$\begin{array}{l}\text { Explain the causes } \\
\text { of tooth decay } \\
\text { in young children }\end{array}$} & pre & $206(13.0 \%)$ & 649 (40.8\%) & $505(31.8 \%)$ & 151 (9.5\%) & 79 (5.0\%) \\
\hline & post & $9(0.6 \%)$ & 59 (3.7\%) & 702 (44.2\%) & 792 (49.8\%) & 28 (1.8\%) \\
\hline & Difference & $12.3 \% \downarrow$ & $37.1 \% \downarrow$ & $12.4 \% \uparrow$ & $40.3 \% \uparrow$ & $3.2 \% \downarrow$ \\
\hline \multirow{3}{*}{$\begin{array}{l}\text { Explain how to prevent } \\
\text { tooth decay } \\
\text { in young children }\end{array}$} & pre & 133 (8.4\%) & $646(40.6 \%)$ & 569 (35.8\%) & $170(10.7 \%)$ & $72(4.5 \%)$ \\
\hline & post & 2 (0.1\%) & 49 (3.1\%) & $680(42.8 \%)$ & 705 (44.3\%) & 154 (9.7\%) \\
\hline & Difference & $8.3 \% \downarrow$ & $37.5 \% \downarrow$ & $7.0 \% \uparrow$ & $33.6 \% \uparrow$ & $5.2 \% \uparrow$ \\
\hline
\end{tabular}

and accommodation costs, or travel time, and allows learners to participate no matter where they are located geographically.

A 2010 Canadian study ${ }^{17}$ examined the effectiveness of oral health capacity-building workshops provided to service providers and community members who work with infants and preschool children. The results showed that, prior to the workshop, many of the study participants were unfamiliar with the recommended age of a first dental visit, how to assess caries risk, and how to identify early stages of decay. Self-reported data 1 month later suggested that participants changed behaviours as a result of what they learned. Non-dental professionals were used in delivering the workshop, suggesting that health professionals without formal dental training, but who possess health promotion skills, can share basic oral health information that can lead to improved awareness and knowledge of oral health among service providers and community members. Using non-dental professionals to train childcare educators could be considered to reduce the costs of delivering the NSW Little Smiles sessions.

A limitation to this evaluation is that there is no information about longer-term impacts and outcomes of the sessions (e.g. retention of knowledge/confidence over time, changes in practice in childcare settings, or changes in oral health status). Subsequent to the implementation of any changes to improve the organisation and session delivery of these training sessions, future evaluation of the program should include such measures.

Since the establishment of the NSW Little Smiles Program in 2008, a National Quality Framework for long day care, family day care, outside school hours care and preschools (education and care services) has been developed. The National Quality Framework, which is underpinned by the Education and Care Services National Law ${ }^{18}$ and Education and Care Services National Regulations, ${ }^{19}$ sets the National Quality Standards and regulatory framework for education and care services. $^{20}$

The National Quality Standard for oral health falls under Quality Area 2: Children's health and safety; Standard 2.1: Each child's health is promoted; Element 2.1.3: Effective hygiene practices are promoted and implemented.

Learning about healthy lifestyles, including nutrition, personal hygiene (such as dental hygiene and ear care), physical fitness, emotions and social 
relationships, is integral to children's wellbeing and self-confidence. As children become more independent, they can take greater responsibility for their own health, hygiene and personal care and they become aware of their own and others' safety and wellbeing. (p. 47)

Since this evaluation COHS and the NSW Department of Education and Communities have partnered to increase the oral health skills and knowledge of NSW TAFE students in the unit of competency, Ensure the Health and Safety of Children (CHCCN301C), ${ }^{21}$ which is applicable to a number of childrens' services courses. The following progress has been made:

- An oral health resource has been developed and will be provided by TAFE teachers to students across NSW in 2014.

- In September 2013 a submission was presented to the National Skills Standards Council, which is responsible for developing and maintaining the national standards that regulate the vocational education and training sector, requesting the strengthening of oral health skills and knowledge in CHCCN301C.

- $\mathrm{CHCCN} 301 \mathrm{C}$ has been superseded by CHCECE002, ${ }^{22}$ which has produced significant changes to Element 3 : Implement effective hygiene and health practices; and Performance Criterion 3.2: Support children to learn personal hygiene practices. Students must now be able to demonstrate knowledge of how children's oral health impacts on their general health and well-being, including signs of tooth decay. These changes, endorsed by the Ministerial Council for Tertiary Education and Employment, require all Industry Skills Councils to transition their training packages by December 2015 .

These changes: (i) complement the requirements of Oral Health 2020: A Strategic Framework for Dental Health in $N S W^{23}$ to "encourage non-dental professionals to undertake relevant modules in oral health"; and (ii) will result in students having appropriate oral health knowledge and skills once they enter the childcare workforce.

\section{Conclusion}

Currently, in Australia all childcare services must address oral health in their licensing regulations. This evaluation showed that participation in an education strategy can increase childcare educators' confidence in areas of competence pertaining to oral health issues that meet national quality standards for education and care services. This, and the strengthening of oral health skills and knowledge for childcare services students, can strategically increase the oral health platform in education and care services in NSW. Further long-term evaluation is required to determine if the information has transferred to embedding oral health into policy and daily practice and if this can make a difference to the oral health status of children in care. In addition, other options need to be pursued to provide this information in a more cost-effective way.

\section{Acknowledgments}

The author acknowledges the Local Health District Oral Health Promotion Coordinators who provided detailed reports of the dental information sessions that were held in their Local Health District; Greer Dawson and John Skinner for their expertise and advice; and all session participants who completed evaluation forms and questionnaires. Additional appreciation needs to be given to the NSW Oral Health Promotion Network working party that developed the oral health resource for TAFE NSW.

\section{References}

1. American Academy of Pediatric Dentistry. Policy on early childhood caries (ECC): classifications, consequences, and preventive strategies. Pediatr Dent 2011; 33(6): 47-9.

2. Douglass JM, Douglass AB, Silk HJ. A practical guide to infant oral health. Am Fam Physician 2004; 70(11): 2113-20.

3. Ripa LW. Nursing caries: a comprehensive review. Pediatr Dent 1988; 10(4): 268-82.

4. Locker D, Matear D. Oral disorders, systemic health, well-being and quality of life. Community Health Services Research Unit. Toronto: Faculty of Dentistry, University of Toronto, Canada; 2010.

5. Schroth RJ, Harrison RL, Moffatt ME. Oral health of indigenous children and the influence of early childhood caries on childhood health and well-being. Pediatr Clin North Am 2009; 56(6): 1481-99. doi:10.1016/j.pc1.2009.09.010

6. Armfield JM. High caries children in Australia: a 'tail' of caries distribution. Aust Dent J 2005; 50(3): 204-6. doi:10.1111/ j.1834-7819.2005.tb00362.x

7. Centre for Oral Health Strategy NSW. The New South Wales Child Dental Health Survey 2007. Westmead: Centre for Oral Health Strategy NSW; 2009. Available at: http://www.health. nsw.gov.au/pubs/2009/pdf/cdhs_2007.pdf (Cited 28 October 2013).

8. Kowash MB, Pinfield A, Smith J, Curzon ME. Effectiveness on oral health of a long-term health education programme for mothers with young children. Br Dent J 2000; 188(4): 201-5.

9. Gupta RS, Shuman S, Taveras EM, Kulldorff M, Finkelstein JA. Opportunities for health promotion education in child care. Pediatrics 2005; 116(4): e499-505. doi:10.1542/ peds.2005-0467

10. Office of Communities. Commission for Children and Young People. Early childhood education and care. Available at: http://picture.kids.nsw.gov.au/childcare-and-education/ Early-Childhood-Education-and-Care (Cited 28 October 2013).

11. National Childcare and Accreditation Council. Quality Improvement and Accreditation System: Quality Practice Guidelines. 1st ed. 2005. Available at: http://ncac.acecqa.gov. au/reports/report-documents/qias_trends_june08.pdf (Cited 7 December 2013).

12. Rogers JG. Evidence-based oral health promotion resource. Prevention and Population Health Branch, Government of Victoria. Melbourne: Department of Health; 2011.

13. NSW Little Smiles: dental health resource package for childcare professionals. Available at: http://www.health.nsw.gov.au/pubs/ 2009/nsw_little_smiles.html (Cited 28 October 2013). 
14. Community Services and Health Industry Skills Council. Development of Oral Health Competencies for the Community Services and Health Workforce. Available at: http://www.cshisc. com.au/learn/cshisc-projects/development-of-oral-healthcompetencies-for-the-community-services-and-healthworkforce/ (Cited 28 October 2013).

15. American Academy of Pediatric Dentistry. Policy on oral health in childcare centres. Council on Clinical Affairs. AAPD Reference Manual 2011; 33(6): 33-4.

16. U.S. Department of Education, Office of Planning, Evaluation, and Policy Development. Evaluation of Evidence-Based Practices in Online Learning: A Meta-Analysis and Review of Online Learning Studies. Washington, D.C.; 2010.

17. Macintosh AC, Schroth RJ, Edwards J, Harms L, Mellon B, Moffatt M. The impact of community workshops on improving early childhood oral health knowledge. Pediatr Dent 2010; 32(2): 110-7.

18. Australian Children's Education and Care Quality Authority. National Law. Available at: http://www.acecqa.gov.au/ national-law (Cited 6 December 2013).
19. Australian Children's Education and Care Quality Authority. National Regulations. Available at: http://www.acecqa.gov.au/ national-regulations (Cited 6 December 2013).

20. Australian Children's Education \& Care Quality Authority. Guide to the National Quality Standard. October 2011. Available at: http://cccensw.org.au/wp-content/uploads/guide-to-thenational-quality-standard.pdf (Cited 6 December 2013).

21. Australian Government. Unit of competency details: CHCCN301C - Ensure the health and safety of children (Release 1). Available at: http://training.gov.au/Training/ Details/CHCCN301C (Cited 7 December 2013).

22. Australian Government. Unit of competency details: CHCECE002 - Ensure the health and safety of children (Release 1). Available at: http://training.gov.au/Training/ Details/CHCECE002 (Cited 7 December 2013).

23. NSW Ministry of Health. Oral Health 2020: A Strategic Framework for Dental Health in NSW. Available at: http://www. health.nsw.gov.au/oralhealth/Pages/oral_health_2020.aspx (Cited 28 October 2013). 